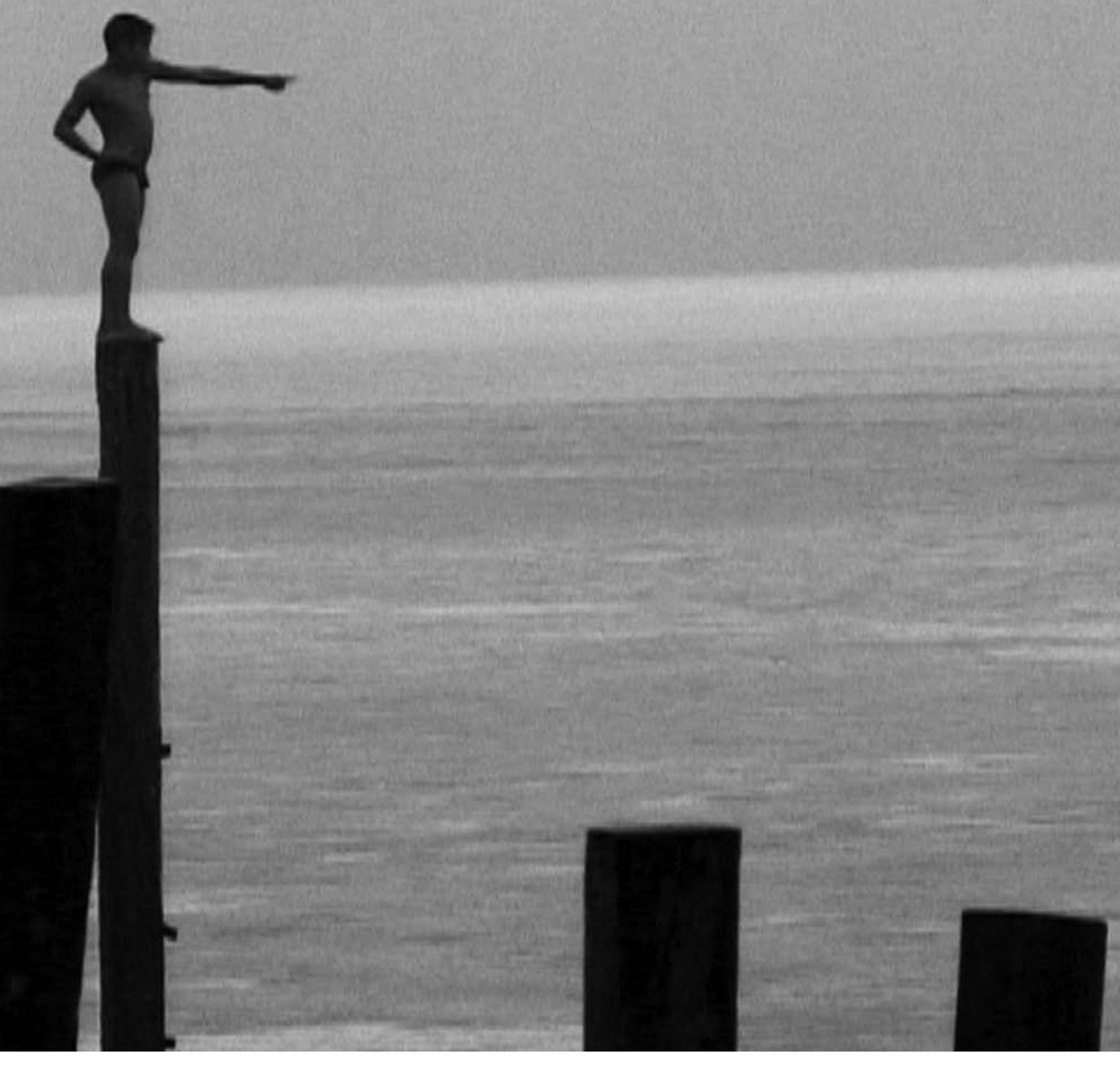




\section{ARTE E NOVAS MÍDIAS: PRÁTICAS E CONTEXTOS NO BRASIL A PARTIR DOS ANOS 90}

É possível observar nas poéticas produzidas mais recentemente no Brasil por meio dos diálogos com as novas mídias a vigência de condutas de caráter mais inespecífico no que tange a suas interlocuções entre múltiplos circuitos, linguagens e campos criativos. É na direção de um mapeamento heterogêneo e disforme que será traçada uma breve leitura sobre como estas práticas, regidas pelo pluralismo e pelos processos de hibridização nas artes, são incorporadas na contemporaneidade, e, por que não dizer?, reconfiguradas, ao modo antropofágico, de tal forma a não se constituírem como um campo específico das manifestações artísticas.

O caráter de antropofagia tem sido constantemente associado na composição de uma visão brasileira de arte, e é tido, muitas vezes, como uma designação já desgastada. Tal conceito, referente aos canibais que viviam na América Latina, remete ao movimento vanguardista brasileiro dos anos 1920 Pau Brasil e, mais recentemente, nos anos 60, ao ideário estético do Tropicalismo. Trata-se de um modo de deglutição cultural, ou um modo de ressemantizar, ou reprocessar, significados preexistentes.

Cabe pensar no caráter antropofágico da arte produzida com as novas mídias a partir dos anos 90 no Brasil. Por um lado, pelo fato de se tratar de linguagens híbridas e de estar inserida numa cultura digital traduzida pela noção do remix e, por outro lado, pelas trocas que estabelece com as mais variadas práticas e circuitos artísticos. Os artistas que dela fazem parte não apenas se apropriam de experiências relacionadas aos ambientes tecnológicos, como também os reconfiguram sob a forma de diálogos intertextuais: transformam estes ambientes em proposições poéticas inusitadas. Esta produção se inclina hoje pela saída dos ambientes específicos da arte-tecnologia, deglute experiências externas e transforma-as em novos pontos de vista.

No Brasil, a partir dos anos 50 e 60, iniciam-se os estudos e os trabalhos criativos acerca das relações entre a comunicação e a arte sob diferentes perspectivas. Entre os anos 70 e 90 as práticas com os novos meios atingem uma maturidade com a exploração das possibilidades expressivas da linguagem. Desde então, não cessam de ampliar-se os interesses sobre as formas de produção simbólica com os processos comunicacionais. Nesta direção, há a expansão do imaginário por meio das tecnologias videográficas, do computador, da internet, da realidade virtual, das redes de comunicação móveis, da inteligência artificial e da engenharia genética.

A partir da passagem para o século 21 , com os substratos da cibercultura, da presença indissociável da internet na vida social, dos mais variados modos de processamento e de circulação das mídias, das dinâmicas de inteligência coletiva, das comunidades virtuais, do acesso a bancos de dados 
1. COUCHOT, Edmond. A tecnologia na arte: da fotografia à realidade virtual. Porto Alegre: Editora da UFRGS, 2003 p. 265-269. on-line, da rotina com os videogames e do convívio banalizado com o contexto hipermidiático de forma geral, torna-se possível observar estas novas redes de sentido produzidas no Brasil como um reflexo da popularização dos meios digitais. Tais redes de sentido se apresentam sob a perspectiva de uma "especificidade diferenciada”, limítrofe e descentralizada.

No campo das estratégias sensíveis da arte contemporânea, há o convívio destas manifestações com aquilo que Edmond Couchot denomina "desespecificação das práticas artísticas”" e que revela, segundo ele, uma hibridação generalizada estendida agora a todo universo dos modelos fornecidos pela tecnociência.

Compreender a produção criativa contemporânea com os novos meios através de uma visão descentralizada diz respeito a conhecê-la de maneira plural, inserida num contexto mais amplo, a partir dos diálogos entre o repertório comum da arte e o universo da ciência e da tecnologia. São como práticas inconformadas - disformes seria um termo melhor balizado. $\mathrm{O}$ termo disforme surge nesta análise por se tratar de uma lógica poética do desvio e da contaminação. É como uma maneira de perceber, antropofagicamente, um tipo de caráter especial, no qual assumidamente se considera não haver caráter específico algum. Interessa mais para esta análise, portanto, encontrar as misturas, os híbridos, ou aquilo que não é constituído por nenhum caráter particular nestas práticas artísticas.

Temos convivido, neste início de século 21, no Brasil, com trabalhos de novas mídias que provocam uma maior contaminação entre os circuitos da arte e da vida, o embate direto em torno do espaço público e uma postura mais crítica em relação aos meios tecnológicos. Estes trabalhos suscitam, por conseguinte, discussões de cunho mais político. Eles se situam em zonas fronteiriças: ora inserem-se no contexto institucional (como os que são produzidos com o apoio de instituições culturais e científicas), ora inserem-se em contextos alternativos, não-oficiais, ou em circunstâncias tidas como menos protegidas. A questão é saber como é possível mapear esta produção criativa, tanto em uma quanto em outra tendência, bem como saber como os artistas se defrontam, por meio desta dialética, no ambiente expressivo.

É possível observar, nas poéticas tecnológicas geradas recentemente no Brasil, a vigência de práticas mais inespecíficas no que tange a suas interlocuções entre múltiplos circuitos e campos criativos. É na direção de uma inscrição disforme e heterogênea que será traçada, a seguir, uma dimensão contextual de como estas práticas, regidas pelo pluralismo, são incorporadas, e por que não dizer? - devoradas, de tal forma a não mais constituírem um campo específico das manifestações artísticas.

As poéticas de intervenção digital existentes hoje no Brasil são analisadas, desta forma, como trabalhos na construção de redes de relações sociais em várias frentes. São como redes de colaboração que ampliam a noção de ambiente artístico. A seguir, para melhor explorarmos as tendências acima mencionadas - como zonas fronteiriças em que cada um tenciona interferir e 
alterar a realidade do outro -, serão atribuídas as seguintes leituras para cada uma destas realidades: poéticas investigativas e poéticas da wired city.

\section{Poéticas investigativas}

As poéticas investigativas com as novas mídias atuam na lógica do fazer-pensar arte e tecnologia ao modo de laboratórios vivos e experimentais, nas confluências existentes entre a produção de conhecimento e a produção artística. Este é o ponto de vista de criadores como Julio Plaza. A problemática das poéticas digitais e seus processos de hibridização perpassa praticamente todo o seu projeto de pesquisa. Falecido em 2003, desde o final da década de 1960 Plaza desenvolveu seu discurso crítico-sensível na interface entre a arte, a ciência e a tecnologia. É um dos mais originais representantes do conceitualismo no Brasil. Seu interesse questionador referente às linguagens em contextos híbridos fez com que explorasse um novo pensamento para a arte: a tradução intersemiótica.

Como tradutor intersignos, em contato com os concretistas Décio Pignatari, Augusto e Haroldo de Campos, Plaza parte da poesia visual e pesquisa as novas mídias a partir da década de 1980. Seu campo de ação situase em torno do videotexto, dos painéis eletrônicos de publicidade, da sky art, da holografia, das imagens digitais e da interatividade. Exerce uma forte presença no painel brasileiro, tanto como artista, teórico, curador e crítico, quanto como professor e orientador de uma grande parcela de artistas. Além de um relevante trabalho teórico e curatorial em torno das linguagens eletrônico-digitais, ele realizou também uma série de experiências pioneiras no Brasil em contextos interativos e telemáticos e foi uma das presenças mais estimulantes e investigativas no decorrer dos anos de 1980 e 1990.

Percursos como o de Plaza podem ser observados também em artistas como Philadelpho Menezes, Diana Domingues, Regina Silveira, Eduardo Kac, Gilbertto Prado, Silvia Laurentiz, Suzete Venturelli, Tânia Fraga, Artur Matuck, André Parente, Kátia Maciel, Analívia Cordeiro, o grupo SCIArts (Fernando Fogliano, Milton Sogabe, Renato Hildebrand e Rosangella Leote) e o Poéticas Digitais (ECA-USP), Daniela Kutschat e Rejane Cantoni, entre outros. Estes criadores dialogam, no âmbito científico, com abordagens experimentais para as linguagens tecnológicas e inserem seus trabalhos no campo da invenção em novas mídias.

Philadelpho Menezes é outro criador que, assim como Julio Plaza, origina-se na poesia visual. Ele produz interfaces pela transposição de linguagens, como no caso das suas poesias sonoras, dos vídeos Antologia poética da língua das vogais, Nomes impróprios, Canto dos adolescentes e do CD-Rom Interpoesia (em conjunto com Wilton Azevedo), em que faz interagir a verbalidade, a visualidade e a sonoridade da poesia em meio a contextos videográficos, telemáticos e digitais. Falecido em 2000, ele proporcionou, com seu trabalho, modificações no sistema poético e criou uma outra relação, ou uma nova pro- 
2. Estas questões encontram-se mais aprofundadas no artigo "A experiência com a poética de Philadelpho Menezes". (MELLO, Christine. A experiência com a poética de Philadelpho Menezes. In: BARROS, Anna e SANTAELLA, Lucia (orgs.). Mídias e artes: os desafios da arte no início do século XXI. São Paulo: Unimarco Editora, 2002, p. 27-31.)

3. RUSH, Michael. New media in late 20th-century art. Londres: Thames \& Hudson, 1999 p. 198.

4. O registro do trabalho encontra-se na internet, em www.ekac.org/ teleporting.html.

5. DONATI, Luisa Paraguai e PRADO, Gilbertto. Utilizações artísticas de imagens em direto na world wide web. In: Anais do $1^{\circ}$

Encontro Internacional de Arte e Tecnologia. Brasília: Universidade de Brasília, 1999, p. 88 priedade, para os elementos constitutivos do enunciado ${ }^{2}$ : uma poética da interpenetração de linguagens que expande as particularidades tecnológicas.

Diana Domingues dirige, em Caxias do Sul, o grupo de pesquisa Artecno (www.artecno.ucs.br). Em suas obras, ela expande estratégias de mobilidade entre o nosso corpo e o contexto tecnológico. Ela apresenta, em 1991, a videoinstalação Paragens, na " $21^{\text {a }}$ Bienal Internacional de São Paulo", constituída pelos segmentos Olho (um espelho d'água), Clareira (sete monitores, representando os sete dias da criação) e Muro (uma vídeo-janela na forma de um monitor de 28 polegadas com cenas de paisagens). Em 1994, Domingues expõe no Museu Nacional de Belas Artes, no Rio de Janeiro, a videoinstalação In-viscera, contando com imagens científicas extraídas de videolaparoscopias de vísceras vivas. Em 1997, apresenta a videoinstalação interativa Trans-e:my body, my blood, em que conjuga imagens de vídeo pré-gravadas com imagens em tempo real, associadas a sistemas computacionais que geram interação entre o espectador e a obra. A partir de 2002 realiza o projeto Ouroborus, calcado em três ambientes de realidade virtual: em Village, ela explora o ambiente remoto, em Serpentarium, a robótica e a telepresença, e em Terrarium, a vida artificial. A metáfora por ela gerada nestes trabalhos diz respeito à idéia de mover-se, estabelecer trocas com o desconhecido e deslocarse em novas relações com o ambiente virtual.

No campo dos desterritórios das redes telemáticas, onde espaço e tempo não são separados por distâncias geográficas ${ }^{3}$, é possível observar certas experiências produzidas no Brasil com o tempo real por artistas como Eduardo Kac, Gilbertto Prado, Bia Medeiros e o grupo Corpos Informáticos. Para eles, as novas mídias participam da organicidade de seus trabalhos muito mais como um gesto, um ato ou uma possibilidade de comunicação. Desta maneira, performances ao vivo tomam lugar na internet, acontecendo muitas vezes de forma mediada pela telepresença e por web-câmeras.

Eduardo Kac (http://www.ekac.org) é outro artista que origina-se na poesia visual e traça um profundo caminho internacional no âmbito das investigações tecnológicas. Entre uma vasta obra realizada, em 1996 ele empreende a instalação interativa Teleporting an unknown state ${ }^{4}$, em que anônimos do mundo inteiro apontam suas web-câmeras para o céu e transmitem - por meio da internet - a luz do sol para o interior de uma galeria de arte, onde os fótons capturados pelas câmeras são direcionados para o crescimento de uma planta. Estas imagens, captadas em tempo real de lugares remotos, são "despojadas de qualquer valor de representação pictórica, formal, plástica, e usadas como transportadoras de ondas de luz" . Kac recicla e subverte, assim, o uso tecnológico, ao mesmo tempo em que oferece novos sentidos para ele. Numa primeira exibição deste trabalho, o processo inteiro de crescimento da planta foi transmitido ao mundo pela internet, permitindo que os participantes acompanhassem os resultados de sua intervenção na obra. Recentemente, em 2004, o mesmo processo foi reapresentado em São Paulo no decorrer da exposição “Emoção Artificial 2", com curadoria de Arlindo Machado e Gilbertto Prado.

120 Mello 
Grande parte da sua poética reside na exploração da natureza dos códigos, da vida vegetal simulada e da comunicação humana com os ambientes inteligentes e sintéticos.

Gilbertto Prado (http://wawrwt.iar.unicamp.br), artista e pesquisador que desenvolve trabalhos em arte-comunicação desde os anos 80, empreende ao longo de sua trajetória uma série de estratégias diferenciadas de atuação a partir do tempo real e das redes artísticas. Em agosto de 1991 - no contexto da exposição "Luz Elástica", organizada por Eduardo Kac no Museu de Arte Moderna do Rio de Janeiro -, Prado participa de um projeto de telescanfax, cujo processo consistia, nas palavras do próprio autor, na "leitura de imagens de televisão com scanner de mão e o envio destas imagens transformadas a um outro local via fax-modem”. Conforme explica Prado, graças à composição dos movimentos de leitura entre o scanner (meio numérico) e a varredura da imagem videográfica (meio analógico), obtinha-se uma imagem decomposta, embaralhada, de aspecto enigmático ${ }^{6}$. Seu trabalho, denominado La vendeuse de fer à repasser, foi enviado de Paris para o grupo de artistas que se encontrava no Rio de Janeiro.

O projeto de Gilbertto Prado Moone: La Face Cachée, realizado em 1992 durante a exposição "Machines à Communiquer - Atelier des Réseaux", na Cité des Sciences et de l'Industrie, em Paris, é mais um exemplo constituído no cerne híbrido das redes artísticas. As primeiras imagens foram realizadas entre os Electronic Cafe de Paris e de Kassel ("Documenta IX"), na Alemanha. Para Prado, a proposição deste projeto consiste em "construir com um parceiro distante (e eventualmente desconhecido) uma imagem híbrida e composta em tempo real. Esta ambigüidade está na raiz da proposição de se criar uma relação efêmera, onde o crescimento e a composição da obra dependem de uma dinâmica de intercâmbio"’.

Em 1995, Gilbertto Prado realiza, no MAC-USP, M.A.(desejo), uma instalação interativa que, entre outros elementos, disponibiliza uma câmera de vídeo que permite ao espectador se ver em posição de voyeur. Em 1998, ele apresenta no Paço das Artes, em São Paulo, a web-instalação Depois do turismo vem o colunismo, que consiste em um portal monitorado por duas câmeras de vídeo conectadas à internet.

A partir de experiências como estas, em tempo real, Prado expande sentidos para a imagem em movimento, transmutando-a alternadamente para os espaços híbridos, bem como fazendo-lhe (re)ligar dimensões diferentes entre o espaço físico e o espaço virtual, como ocorre em seu trabalho Desertesejo ${ }^{8}$. Este trabalho é um ambiente virtual interativo multiusuário construído em VRML e disponibilizado na internet. Em estratégia inversa aos jogos, este videogame transforma o espaço público da internet no espaço da poiesis, em uma busca dialética e onírica pelo Outro. A grande interface, nele, é a sensorialidade proposta aos agenciadores da obra. Neste ambiente multiusuário, o deserto e o desejo fascinam, tanto quanto os sons, a tendência ao silêncio e a dinâmica de convivência em espaços lisos, sob as diferentes visões
6. PRADO, Gilbertto. As redes artísticotelemáticas. Revista Imagens. $n .3$. Campinas: Unicamp, 1994, p. 42.

7. Idem, p. 43.

8. Ver www.itancultural.org.br/desertesejo. 
9. O grupo é coordenado por Bia Medeiros e atualmente fazem parte dele Carla Rocha, Cila

MacDowell, Cyntia

Carla, Maria Luiza

Fragoso, Alice Stefania Curi, Robiara Beccker e Viviane Barros.

Para uma melhor

compreensão da

abrangência de suas atividades, procurar em http://corpos.org.

10. KUTSCHAT HANNS, Daniela. Corpo-espaço: notas, rotas e projetos. Tese

de Doutorado. São Paulo: Escola de Comunicações e Artes da USP 2001, p. 61-63.

de um mesmo mundo compartilhado em tempo real.

Outro campo de pesquisa desenvolvido nos anos 1990 e relacionado às questões do corpo nos cruzamentos do vídeo e das novas tecnologias refere-se ao trabalho de Bia Medeiros e do grupo Corpos Informáticos ${ }^{9}$. Constituído em 1991, este grupo conduz suas atividades no enfrentamento das questões de caráter vivencial do corpo, no embate ao vivo, mediado por câmeras de vídeo ou por web-câmeras, em torno de performance digital, videoinstalações, net art e telepresença. Em 2002, o grupo realiza Macula@corpos, performance em telepresença apresentada em São Paulo no " $1^{\circ}$ Circuito Centro da Terra de Artes Cênicas”. Neste trabalho, web-câmeras interagem com o corpo dos espectadores e estas interações são transmitidas, simultaneamente, tanto para um circuito interno de monitores de vídeo e de computadores (localizado no interior do teatro), quanto on-line, pela internet.

Daniela Kutschat amplia fronteiras no vídeo digital ao realizar Vôo cego I e Vôo cego II, em 1998, por meio de animações criadas a partir de imagens videográficas que hibridizam, em sua gênese, procedimentos analógicos e digitais. Utiliza a câmera de vídeo para captar dimensões de um mesmo espaço ou de espaços diferentes em movimento e, posteriormente, trabalha-as digitalmente. Como Kutschat analisa, essas "imagens estão repletas de ruídos que, se fossem nítidos, seriam imediatamente percebidos como colagens ou superposições. Entretanto, sendo esmaecidos e desfocados, editados e montados dessa forma, são 'neo-realidades' sintéticas" ${ }^{10}$. É interessante notar que mesmo no título destes trabalhos de Daniela Kutschat já se encontram inseridas questões conceituais advindas do confronto analógico-digital. É possível refletir que se trata de um vôo cego por se relacionar a uma discussão metafórica entre a capacidade de ver, captar e registrar imagens do mundo físico (possibilitada pelos sistemas ópticos, como o da câmera videográfica) e esta mesma incapacidade na constituição da imagem sintética. O computador é reconhecido justamente por sua característica oposta de, em vez de extrair as imagens do mundo real, poder concebê-las, construí-las diretamente em sua própria constituição sígnica numérica, por meio de linguagens como a realidade virtual.

Um pouco antes da passagem para os anos de 1990, em 1987, Rejane Cantoni realiza, durante um curso na ECA-USP com o artista catalão Antoni Muntadas, aquela que vem a ser provavelmente uma das primeiras experiências de videoinstalação interativa em nosso país. Trata-se de Ao vivo, trabalho em que o interator, ao entrar no ambiente, dispara um alarme e o sistema de vídeo. Na tela dos monitores, um revólver é apontado para o usuário, que se transforma em vítima de sua observação. Assim que o disparo é ouvido, entra o título do trabalho e uma luz é acesa apontando o caminho da saída. Após uma série de pesquisas e experiências criativas, já em 1999, Rejane Cantoni empreende, com Daniela Kutschat, no Paço das Artes em São Paulo, a videoinstalação Máquinas de ver I. Neste trabalho, as imagens são captadas em tempo presente por meio de um circuito fechado de vídeo, incorporam o visitante e o ambiente físico e são simultâneas e opostas entre si. 
Daniela Kutschat e Rejane Cantoni realizam também de forma conjunta o trabalho intitulado OP_ERA (http://www.op-era.com) no decorrer da primeira década do século 21. Conforme elas afirmam, este trabalho é um mundo computacional composto de quatro dimensões interligadas por passagens, que o visitante vai descobrindo ao explorar cada uma destas dimensões. Produzido sob a forma de um espaço matemático progressivo, o projeto possui uma série de desdobramentos. Trata-se de imergir o corpo de forma performática e interativa no espaço sensório por meio de experiências rítmicas, cinéticas, vibracionais e do uso de interfaces táteis e sonoras. É uma forma de ampliação da vivência estética para além do espaço da obra, para o espaço da vida e das relações com o "outro" maquínico, virtual, cuja maior experiência se dá no campo da linguagem, no campo da transformação e da construção dos sentidos.

Em interlocução com o pensamento de Merce Cunningham, a coreógrafa e pesquisadora Ivani Santana desenvolve trabalhos no campo da dança e das mediações tecnológicas desde 1994. Sua coreografia Gedanken (2000) trata da viagem de um corpo por experiências imaginárias. Nela, o corpo físico é dimensionado em várias existências. Conforme explica Santana, trata-se de uma viagem que não começa em cena, pois há corpos projetados que recepcionam o público, e o palco e a platéia transformam-se numa grande instalação. Desta maneira, o espaço cênico é constituído de corpo e de luz. Neste trabalho, ela utiliza uma microcâmera de vídeo no joelho e outra no olho, funcionando em um sistema de circuito fechado para transmissão em tempo real. Há projeções de imagens do software Life Forms, no qual foram criadas as frases de movimento do espetáculo. Há também o uso do software Image-ine para processamento de imagem em tempo-real, bem como a projeção de imagens e textos enviados pelos usuários da internet.

Mais recentemente, podemos exemplificar também trabalhos realizados na forma de sistemas interativos conjugados à telefonia móvel por meio de interfaces entre música, corpo e movimento, como é o caso de obras criadas em 2005 por Analívia Cordeiro, assim como na forma de vídeo interativo, ou videogame, como é o caso do trabalho de Márcia Vaitsman, produzido com o apoio da Alemanha e do Japão, em que o agenciador adquire um ponto de vista mutante e intercambiável.

Este conjunto de criadores integra e bem exemplifica um grupo de artistas brasileiros que desenvolve estratégias de presentificação do tempo de forma compartilhada, inseridas no contexto da arte digital e telemática. Chamar atenção para as práticas midiáticas produzidas nas confluências com o contexto do jogo, da dança e das performances multimídia é abordar poéticas híbridas e midiáticas em tempo real, poéticas impermanentes, transitórias, que expandem a idéia de fluxo midiático no universo da arte e que são capazes de dialogar hoje com a ampla gama de procedimentos criativos relacionados ao âmbito da cultura digital.

Observam-se, neste conjunto de proposições, investigações interdisci- 
11. PLAZA, Julio e TAVARES, Monica. Processos criativos com os meios eletrônicos: poéticas digitais. São Paulo: Hucitec, 1998, p. 97. plinares e circunstâncias diferenciadas do processo de elaboração artística: a transformação da idéia dá-se por mecanismos de contaminação e hibridação entre os meios tecnológicos. Trata-se de criadores que encontram em suas poéticas o embate direto com o tempo ubíquo do ciberespaço e geram uma série de trabalhos que subverte-altera-amplia o sentido inicialmente previsto para o contexto eletrônico-digital - quer seja em torno da discussão temporal, quer seja em torno das novas formas de experimentação estética, conseguindo a difícil tarefa de conciliar o circuito da arte às mídias de rede.

Estes procedimentos visam eminentemente esgarçar a dimensão temporal da arte para novas realidades, inserir critérios diferenciados de autoria que passa a ser compartilhada e agenciada pelo público - e também articular a vivência da obra como parte intrínseca ao trabalho artístico.

Julio Plaza e Monica Tavares, ao analisarem os métodos de criação artística, chamam atenção para o fato de que "a operação artística é um processo de invenção e produção”. Eles analisam cerca de dez modos de operar as novas tecnologias. Entre eles, há o método dos limites. Para os autores, o método dos limites consiste em "explorar as leis, normas e regras que definem um projeto, na tentativa de nelas reconhecer as fronteiras do seu campo de atuação para, a partir daí, poder transgredi-las”" ${ }^{11}$ Se na concepção do método dos limites, segundo Plaza e Tavares, para se criar deve-se quebrar os limites impostos pelo meio, estas regras são constantemente atualizadas por este conjunto de criadores, que busca, no limite, processos experimentais para as linguagens das novas mídias.

\section{Poéticas da wired city}

Como um movimento de inteligência coletiva, as poéticas da wired city articulam intervenções no contexto urbano e imprimem um maior questionamento em torno das relações tecnológicas e suas implicações no sistema sociopolítico e econômico. Deliberadamente dissociado do acesso às tecnologias de ponta, este movimento coletivo emergente no Brasil se apropria e reprocessa os ambientes low-tech existentes com atitude crítica. Tal circunstância é assumida como uma forma de instaurar uma visão particular de mundo e furar bloqueios na constituição de um circuito alternativo de arte produzido pelos meios digitais.

No Brasil, eu vivencio esta experiência numa cidade como São Paulo. Uma cidade que é, provavelmente, a que mais compreende, no país, a dinâmica digital. São Paulo é um grande aparelho cultural, uma wired city, como já pensava o filósofo Vilém Flusser nos anos 80. Embora seja uma cidade midiatizada, ela vive, tanto quanto outras metrópoles do país, uma intermitente contradição e negociação entre a lógica do local e do global, entre noções de inclusão e exclusão digital.

Nesta direção, as poéticas da wired city aqui observadas giram em torno de performances no espaço público de lógica mais situacionista, como é 
o caso de: Graziela Kunsch, em seu franco ativismo em torno dos coletivos, comunidades virtuais, instalações e projetos de vídeo; Otávio Donasci, em suas performances multimídia; Giselle Beiguelman, em suas intervenções híbridas pela web, a partir de sites, telefonia-sem-fio e painéis eletrônicos publicitários; Jurandir Muller, Kiko Goifman, Lucas Bambozzi, Rachel Rosalen, Rachel Kogan, Simone Michelin, Lucia Leão, Daniel Seda, Marcelo Cidade, Leandro Lima e Gisela Motta, em suas videoinstalações, net art, documentários e projetos de intervenção digital, telemática e com câmeras de vigilância e sensores eletrônicos; dos músicos Lívio Tragtemberg e Wilson Sukorski; de Daniel Lima e A Revolução Não Será Televisionada, em seus projetos de intervenção em programas televisivos e também nos sistemas públicos midiatizados, como no projeto CUBO (celebração multimídia), organizado de forma coletiva com muitos destes grupos e criadores e apresentado em 2005 no centro de São Paulo.

Este é o caso também de ações efêmeras como os casuais flashmobs, que ocorrem nos grandes centros urbanos; os weblogs, orkuts, vídeos políticos e as net-rádios e fanzines digitais, acionados por coletivos que estabelecem intervenções midiáticas, como Cobaia, Cia. Cachorra, Perda Total, Formigueiro, Metáfora, NeoTao, Horizonte Nômade, Nova Pasta, Base V, Esqueleto Coletivo, Contra-filé e Rejeitados; a contra-informação na escrita do texto científico por Cícero Inácio da Silva; as performances de live images, ou vídeo ao vivo, realizadas pelos VJs na cena noturna eletrônica - como o coletivo Bijari e os VJs-artistas Luiz Duva, Aléxis, Palumbo e Spetto, sendo o trabalho deste último associado também à sampleagem digital, por meio de imagens apropriadas das mais diferentes circunstâncias e mídias, bem como à criação de software aberto e gratuito e à noção de copyleft.

Este conjunto de criadores acima citado explora, muitas vezes, as novas mídias para além dos espaços institucionais da arte e da ciência e vivencia a cidade como uma experiência de subjetivação. Suas ações são realizadas a partir do compromisso com a vida pública e não necessariamente a partir do compromisso com o sistema científico ou da invenção tecnológica.

Um percurso criativo que merece aprofundamento e um maior estudo no campo dos entrecruzamentos entre o teatro, os espetáculos multimídia e as intervenções urbanas é o de Otávio Donasci. Ele cria as suas primeiras videocriaturas $^{12}$ em 1981 e vem desenvolvendo, desde então, toda a sua poética em torno das performances interativas. Donasci trabalha sobre o conceito teatral de máscara. Como considera que o material do seu tempo é o elétron, ele desenvolve rostos virtuais eletrônicos que são aplicados sobre o rosto real como uma segunda pele. Em suas primeiras videocriaturas, Donasci constrói estas máscaras eletrônicas a partir de televisores branco-e-preto fixados na cabeça e orientados de modo "vertical" (formato denominado por ele como "retrato"), acompanhando o formato do rosto e ligados por cabos a um videocassete ou câmera low-tech, único equipamento acessível a ele na época. Conforme explica Donasci, o figurino é uma malha preta de bailarino ou ginasta que, com um capuz, cobre todo o equipamento agregado ao corpo e, ao
12. Videocriatura é, em descrição do próprio Otávio Donasci, um ser híbrido gerado a partir de máscaras eletrônicas, criadas com monitores de vídeo low-tech $e$ acopladas ao corpo de performers por intermédio de próteses ortopédicas. Parte fundamental de seu projeto poético, vem sendo desenvolvida por ele desde a década 
de 1980, em centenas de atuações

e performances

diferentes entre si, que são apresentadas tanto no Brasil quanto

no exterior.

Para um maior

aprofundamento,

procurar em

www.videocriaturas

hpg.com.br.

13. Giselle Beiguelman proferiu palestra sobre arte on-line em 30 de novembro de 2002, na Pinacoteca do Estado de São Paulo, na qual abordou os trabalhos

$e$ as questões aqui relacionados.

14. Para maiores informações sobre este trabalho de Beiguelman, pesquisar em www.desvirtual.com/nike,

bem como no texto curatorial "Na rede". (MELLO, Christine. Na rede. In: $25^{\mathrm{a}}$ Bienal de

São Paulo:

Iconografias metropolitanas Brasil. São Paulo: Fundação Bienal de São Paulo, 2002, p. 165. .)

15. Ver www.desvirtual.com/ egoscopio.

16. Ver www.sescsp. org.br/sesc/hotsites/ paisagem 0 . mesmo tempo, pela semitransparência, dá visão ao performer, permitindo sua movimentação pelo espaço. Recentemente, Donasci vem realizando trabalhos interativos com telas de cristal líquido, bem como espetáculos eloqüentes no espaço urbano. Com uma interface homem-máquina, mistura de meio eletrônico, teatro e performance, Donasci revela o próprio princípio da intermídia, em que o trânsito existente entre uma e outra linguagem é capaz de constituir uma nova categoria expressiva.

Giselle Beiguelman ${ }^{13}$ (http://www.desvirtual.com) elucida muito bem certas questões existentes no campo da arte-tecnologia ao chamar a atenção para o nomadismo que as mídias digitais proporcionam e para a circunstância atual, em que matriz e cópia convivem simultaneamente em um único domínio. Beiguelman introduz no Brasil as práticas poéticas de reciclagem digital com trabalhos constituídos em rede como <content-no cache>, Egoscópio e Ceci n'est pás une Nike ${ }^{14}$. Este último, para Beiguelman, discute justamente o conflito interface-superfície nos processos comunicacionais. No conjunto de seus trabalhos, ela reflete a necessidade de repensarmos novos paradigmas para a criação, assim como uma cultura híbrida, nômade, ligada à reciclagem das mídias e à sampleagem.

O trabalho Egoscópio ${ }^{15}$, de Giselle Beiguelman, uma tele-intervenção que transforma a informação da internet em sinal videográfico, também realizado em 2002, é como um mergulho no universo híbrido das mídias. Trata-se da construção de um ser mediado pela informação, entre a arte, a publicidade e a telecomunicação. Este trabalho estabelece parâmetros de hibridização que confundem as interfaces e as mensagens, em um processo de associação e desconexão entre fragmentos dispersos em inúmeros sites. Trata-se de uma tele-intervenção midiática em espaços públicos que faz com que os contextos e conteúdos gerados em rede, tanto na internet quanto na telefonia móvel, sejam transformados em sinal videográfico e projetados em painéis eletrônicos publicitários distribuídos pela cidade de São Paulo.

Há também o trabalho de Beiguelman Web Paisagem $0^{16}$, realizado em 2002 (em conjunto com Marcus Bastos e Rafael Marchetti). É um trabalho de net art que faz o usuário samplear paisagens nômades da internet por meio da mixagem on-line de arquivos de vídeo, som, imagem e texto de seu banco de dados.

Outro percurso bastante interessante é o do projeto Valetes em slow motion. Este projeto teve início com a produção do vídeo Tereza, de Kiko Goifman (1992, co-direção de Caco Pereira de Souza). Na seqüência foi gerado, por ele também, o CD-Rom Valetes em slow motion (1998, com direção de produção de Jurandir Muller e direção de criação de Lucas Bambozzi), lançado em conjunto com um livro impresso, de caráter teórico (trata-se de pesquisa de mestrado, na área da antropologia, empreendida por Goifman sobre o tempo na prisão, que acompanha a organização dos conteúdos e a reflexão sobre o tema geral do trabalho).

O trabalho deu origem a um site na internet, a uma videoinstalação 
interativa apresentada na "24ª Bienal Internacional de São Paulo" (1998) e a uma outra na " 2 a Bienal do Mercosul" (1999), intitulada Jacks in slow motion: experience 02. Estas últimas etapas do projeto tiveram a co-criação e a codireção de Jurandir Muller. Do meio imaterial e eletrônico do vídeo, o projeto Valetes em slow motion dialoga com os processos não-lineares e interativos da linguagem hipermidiática encontrados no CD-Rom e, na seqüência, expandese como forma híbrida, entre o espaço físico e o virtual, para o contexto das videoinstalações e para os domínios imersivos das redes telemáticas e do ciberespaço.

Já em 2002, Jurandir Muller e Kiko Goifman desenvolvem o projeto Coletor de imagens. O projeto é constituído por um documentário, uma videoinstalação e um site $^{17}$, em que pessoas do mundo inteiro podem enviar suas próprias imagens, de origens as mais diversas, proporcionando um grande contágio entre universos e sentidos bastante diferentes. Trata-se de um projeto de recomposição e ecologia da imagem, em que o artista, ao tomar consciência da grande quantidade de imagens já existente no mundo, em vez de saturá-lo produzindo mais imagens, prefere ressignificar as imagens existentes.

Nele - ao estilo de Oswald de Andrade, que em seu "Manifesto Antropófago" (1928) afirma: "só me interessa o que não é meu" - Goifman e Muller promovem a inversão do processo de criação, iniciando-o pelo ato de recuperar imagens produzidas por pessoas anônimas. Atuam de forma performática ao coletar no espaço público imagens caseiras, esquecidas e inusitadas, oriundas da fotografia, do cinema ou do vídeo, por meio da coleta desses materiais promovida por um carro com um microfone aberto que sai pelas ruas da cidade pedindo estas imagens.

33 (2004), de Kiko Goifman, é cinema das mídias. Por meio da busca detetivesca de sua mãe biológica, Goifman faz o público compartilhar uma experiência situada entre o campo das narrativas pessoais e os jogos em tempo real proporcionados pelos mais diversos circuitos de comunicação. $\mathrm{O}$ trabalho é ao mesmo tempo um diário on-line na internet, uma reportagem na televisão broadcast, um vídeo experimental, um road movie e um documentário performático. Enfim, um cinema contemporâneo, capaz de revelar uma identidade e uma cultura em trânsito, em processo.

É possível verificar na obra de Lucas Bambozzi (http://comum.com/ lucas/) experiências de intervenções e desvios no cerne do próprio meio digital. Ele compartilha em sua obra o contato efetivo direto entre a experiência individual e a experiência pública. Seus trabalhos são como manifestos sobre a intimidade e a identidade em plena era da desmontagem da informação. Para tanto, Bambozzi chama atenção para as formas de controle e invasão da privacidade advindas dos meios tecnológicos.

Em 2002, Lucas Bambozzi apresentou 4 paredes, no Paço das Artes, em São Paulo. Trata-se de um projeto de videoinstalação interativa em que sensores controlados por computador possibilitam convergências do vídeo no meio digital. Encontramos aqui a interface como experiência sensória, um exemplo
17. O endereço do site é wuww.paleotv.com.br/ contagio. 
18. Ver www.eco.ufri. michelin $/ \mathrm{sm} / \mathrm{mmm}$. de trabalho em que importa menos explorar a superfície da imagem e mais as situações de interação entre a obra e o espectador. Um hibridismo muito particular em que a interface e suas articulações pelo ambiente da videoinstalação tornam-se a própria mensagem. A intenção deste trabalho é fazer o usuário se sentir invasor nas relações observador-observado, ser vigiado e vigiar.

A arte, para Bambozzi, diz respeito a colocar em contato, ou em relação, sistemas comunicacionais de partilha e troca com o outro. Neste sentido, para ele, vivenciar a situação do trabalho, a experiência que o mesmo carrega, é inerente à constituição da própria idéia de arte. Seus trabalhos dizem respeito, de um modo geral, ao confronto midiático produzido no encontro com o outro e às relações do sujeito entre a vida pública e a vida privada. Este é o caso de seu projeto Spio, criado a partir da idéia de um robô espião, que foi apresentado na exposição "Emoção Artificial II", em 2004, com curadoria de Arlindo Machado e Gilbertto Prado.

Esta obra faz com que o sujeito, protegido em seu aparente anonimato das câmeras de vigilância, questione até que ponto ele mesmo não acata as situações ilícitas da vigilância e compartilha com o invasor uma mesma realidade. De uma certa maneira, Bambozzi proporciona, neste trabalho, a possibilidade de cada indivíduo se posicionar diante do contexto midiático, observandose tanto na função de invadido quanto na função de invasor.

Trabalhos como estes trazem questões novas para os espaços expositivos dos circuitos da arte. Trata-se de trabalhos de intervenção no campo coletivo que originalmente atuam em espaços não-institucionais. A questão mais premente a ser aqui pensada é: em que medida estes trabalhos se relacionam com os espaços institucionais? Ou seja, como estes trabalhos se relacionam com espaços da arte que ainda não foram penetrados pelas dinâmicas anárquicas das intervenções digitais?

Este projeto de Lucas Bambozzi passou por uma série de negociações, no decorrer da exposição "Emoção Artificial II", com a equipe da empresa terceirizada que presta serviços de segurança ao Itaú Cultural. Tal fato ocorreu também com a intervenção digital de Simone Michelin, presente nesta mesma mostra, ADA: Anarquitetura do Afeto. Esta situação ocorreu por conta de ambos criadores questionarem, em seus projetos, a questão da vigilância e seus mecanismos de ação nos espaços institucionais, questão esta que entrava justamente em confronto com as normas de segurança da instituição.

Simone Michelin cria outros trabalhos, também em novas mídias, como o game de arte para internet $M M M^{18}$, realizado em 2001, em forma de narrativa hipermídia, e o recente Liliput, criado para a inauguração do Centro Cultural Telemar em 2005. Conforme Michelin, neste trabalho ela reflete aspectos das relações de constituição do domínio público, em que o capitalismo globalizado produz próteses tecnológicas cada vez mais sofisticadas que somatizam os desejos humanos.

Como uma espécie de subversão, ou uma metáfora acerca das tensões decorrentes da sociedade de controle, artistas como Bambozzi e Michelin, ao 
lidar com este artifício no contexto de espaços institucionais, sabem muito bem que se trata de um modo de situar suas obras numa zona do controledescontrole. E acredito que faça parte do papel do artista tecnológico saber alargar estas zonas de confronto e embate expressivo nos espaços institucionais, ou espaços mais protegidos.

Lucia Leão (http://www.lucialeao.pro.br), com seu trabalho colaborativo na internet Plural maps ${ }^{19}$, leva o usuário a interagir com web-câmeras espalhadas em pontos específicos da cena urbana. Trata-se de uma intervenção estética na idéia de cidade, em que o fruidor penetra e interage num campo de ação por meio de labirintos no ciberespaço, de web-câmeras fornecidas pelos próprios participantes, e da realidade virtual. Plural maps oferece a consciência da desorientação, a necessidade de mapas que subvertem noções tradicionais de cartografia e refletem um novo tipo de configuração do tecido público imaginário.

Como é possível observar nestes exemplos, os criadores que atuam em torno de poéticas de intervenção digital geram, assim, estranhamento por meio de zonas de tensão entre sistemas midiáticos, entre desvios no sistema urbano e digital, nos sistemas de controle e segurança, e assim por diante. Tal estratégia de ação é similar à idéia de software virótico, por se infiltrar no circuito cultural, nas redes digitais - na tentativa de desconstruir tanto as formas organizadas da vida comum quanto as práticas sensórias.

Fora do controle institucional, da lógica do mercado e, na maior parte das vezes, independentes do contexto científico, estas práticas questionam a liberdade nos meios digitais e apresentam-se como um modo de ocupação do espaço público, na medida em que intervêm no circuito urbano das mensagens comunicacionais.

\section{Novas circunscrições para a arte e novas mídias}

Compreendido em sua descentralização, o contexto das novas mídias no Brasil a partir dos anos de 1990 é, assim, pontuado pelas marcas móveis de suas redes de conexões e extremidades. Por esta lógica, o meio maquínico não é analisado como uma totalidade, mas inserido no conjunto de relações que opera, compartilhando múltiplas formas de interferência nas proposições artísticas e interconectando diversos elementos sensíveis, sem necessariamente problematizar a tecnologia e suas especificidades.

É possível perceber, na intertextualidade promovida por este conjunto de trabalhos, a presença viva dos modos antropofágicos das novas mídias. No universo das mídias, conforme observa Marcus Bastos ${ }^{20}$, as linguagens estão sempre em relação, por isto elas não podem ser pensadas isoladamente. Ele defende o uso do termo sampler - na compreensão do contexto de convergência das mídias na atualidade - como uma cultura da reciclagem semiótica, em que o anônimo, o reciclado e o consumível assumem novos papéis. Bastos relaciona de forma original e inédita a idéia de samplertropofagia (que corresponde
19. Ver

www.lucialeao. pro.br/pluralmaps.
20. BASTOS, Marcus. Samplertropofagia: das relações entre literatura e tecnologia. São Paulo: PUCSP, 2002. (Palestra proferida em25/11/02 
no seminário "Poéticas

Digitais e o Corpo Biocibernético")
21. PLAZA, Julio. O mimético, a interferência e o instante nos MM (mass media). In: BASBAUM, Ricardo(org.). Arte contemporânea brasileira: texturas, dicções, ficções, estratégias. Rio de Janeiro: Rios Ambiciosos, 2001, p. 275 à fusão dos termos sampler e antropofagia), capaz de reunir, em uma só instância, poéticas como as da reciclagem e da apropriação. Para Bastos, a idéia de samplertropofagia inaugura uma forma de produzir sentido que permite, não apenas a colagem e a montagem, mas a reciclagem das mídias-fonte.

Conforme é possível verificar, no início do século 21, o campo das novas mídias no Brasil já se encontra consolidado como linguagem, possui um caminho próprio no circuito das artes e é, em muitos casos, considerado próximo e acessível a uma ampla gama de criadores.

Muitas vezes a difusão de suas obras dissolve-se na cena contemporânea pelo seu caráter transitório e desprovido de materialidade. Estes trabalhos são considerados marginais perante o circuito de arte, assim como demandam das instituições expositivas uma série de equipamentos e tecnologias que estas nem sempre estão aptas a disponibilizar - e cujos custos de locação ainda são altos para os padrões nacionais -, o que infelizmente inviabiliza muitas das suas apresentações. Por seu caráter efêmero, é problemática a maneira como os museus podem acolhê-los em seus acervos, sendo difícil, por todos estes motivos, estabelecer parâmetros precisos no circuito convencional da arte.

Neste sentido, as forças expositivas têm surgido de articuladores envolvidos há muito com o meio eletrônico e provenientes da área teórica e curatorial. Este é o caso de Arlindo Machado, Gilbertto Prado, Ivana Bentes, Vitória Daniela Bousso e Diana Domingues. É marcante também a presença de Solange Farkas, diretora e curadora do Videobrasil (www.videobrasil.org.br) e uma de nossas maiores articuladoras de arte eletrônica em termos internacionais. Bem como de Ricardo Rosas e do site Rizoma (www.rizoma.net), um núcleo de inteligência coletiva que interconecta ações de dentro e fora, entre o pensamento local e global; e da equipe do FILE (http://www.file.org.br), um dos grandes festivais aglutinadores das novas tendências, discussões e exibições no meio digital, composta por Paula Perissinotto e Ricardo Barreto. Ocorrem também novas circunscrições das novas mídias, como as proporcionadas pela equipe do Prêmio Sergio Motta (www.premiosergiomotta.org.br), coordenada por Renata Motta e Daniela Bousso; por Patrícia Canetti, do Canal Contemporâneo (www.canalcontemporaneo.art.br), e por novos críticos como André Brasil, Eduardo de Jesus, Juliana Monachesi, Lucio Agra, Marcus Bastos e Priscila Arantes.

Se o espaço estético é um campo polêmico por não permitir o consenso, encontramos neste conjunto de experiências a oportunidade de religar este microcosmo à renovação do contexto contemporâneo da arte. Assim, a new media art: práticas e contextos no Brasil a partir dos anos 90 é feito uma geléia geral; disforme, sem nenhum caráter, e, como diria Julio Plaza, pode ser considerada como "universos paralelos e simultâneos que tendem a perder seus contornos e fronteiras fixas" ${ }^{21}$. 


\section{Bibliografia complementar}

BEIGUELMAN, Giselle. O livro depois do livro. São Paulo: Peirópolis, 2003.

DELEUZE, Gilles. Crítica e Clínica. Tradução de Peter Pál Pelbart. São Paulo: Ed. 34, 1997.

DOMINGUES, Diana (org.). A arte no século XXI: a humanização das tecnologias. São Paulo: Ed. Unesp, 1997.

. Criação e interatividade na ciberarte. São Paulo: Experimento,

2002.

DONASCI, Otávio. Videocriaturas: análise de videoperformances realizadas entre 1980 e 2001. Dissertação de Mestrado. São Paulo: Escola de Comunicações e Artes da USP, 2002.

HERKENHOFF, Paulo. Antonio Dias - Nexo entre diferenças. In: Antonio Dias: Trabalhos 1965-1999. Lisboa: Centro de Arte Moderna José de Azeredo Perdigão; São Paulo: Cosac \& Naify, 1999.

KAC, Eduardo. Aspects de l'esthétique communicationale. In: BUREAUD, Annick e MAGNAN, Nathalie (orgs.). Connexions: art, réseaux, media. Paris: École Nationale Supérieure des Beaux-Arts, 2002.

. Novos rumos na arte interativa. In: LEÃO, Lucia (org.). Interlab:

Labirintos do pensamento contemporâneo. São Paulo: Fapesp/ Iluminuras, 2002, p. 107-113.

MACHADO, Arlindo. A arte do vídeo. São Paulo: Brasiliense, 1988.

. A ideologia do cinema militante. Revista Cine Olho. n. 8/9. São

Paulo, outubro/ dezembro de 1979, p. 4-7.

. Máquina e imaginário. O desafio das poéticas tecnológicas. $2^{\mathrm{a}}$ ed.

São Paulo: Edusp, 1996.

. O quarto iconoclasmo e outros ensaios hereges. Rio de Janeiro: Rios

Ambiciosos, 2001.

MCLUHAN, Marshall. Os meios de comunicação como extensões do homem. São Paulo: Cultrix, 1974.

MELLO, Christine. Arte nas extremidades. In: MACHADO, Arlindo (org.). Made in Brasil: três décadas do vídeo brasileiro. São Paulo: Itaú Cultural, 2003, p. 143-174.

. Extremidades do vídeo. Tese de Doutorado. São Paulo: Programa de Pós-Graduação em Comunicação e Semiótica da PUC-SP, 2004. 
MENEZES, Philadelpho. A crise do passado. $2^{\mathrm{a}}$ ed. São Paulo: Experimento, 2001 .

NEBEAU, Charles. Eis o fascínio radical, ou o discreto charme da burguesia. Revista Cine Olho. n. 8/9. São Paulo, outubro/ dezembro de 1979, p. 45-6.

PLAZA, Julio. Videografia em videotexto. São Paulo: Hucitec, 1986.

PRADO, Gilbertto. Arte telemática: dos intercâmbios pontuais aos ambientes virtuais multiusuário. Apresentação de Arlindo Machado e Julio Plaza. São Paulo: Itaú Cultural, 2003.

SANTAELLA, Lucia. Culturas e artes do pós-humano: da cultura das mídias à cibercultura. São Paulo: Paulus, 2003.

SANTANA, Ivani. Corpo aberto: Cunningham, dança e novas tecnologias. São Paulo: Educ, 2002.

SCHWARTZ, Jorge. Introdução. In: Da Antropofagia a Brasília: Brasil 19201950. São Paulo: FAAP (Fundação Armando Álvares Penteado)/ Cosac \& Naify, 2002, p. $11-14$.

Christine Mello, doutora em "Comunicação e Semiótica" pela PUC-SP, é pesquisadora no campo da arte e das mediações tecnológicas. Realiza projetos curatoriais em museus, galerias e festivais, tanto brasileiros quanto internacionais. Coordena a Pós-Graduação "Criação de Imagem e Som em Meios Eletrônicos" do Senac-SP, sendo também professora da PUC-SP e da FAAP-Artes Plásticas. 
